\title{
Role of Tumor Necrosis Factor- $\alpha$ in the Pathophysiologic Alterations after Hepatic Ischemia/Reperfusion Injury in the Rat
}

\author{
L. M. Colletti, D. G. Remick, * G. D. Burtch, S. L. Kunkel, ${ }^{*}$ R. M. Strieter, ${ }^{\ddagger}$ and D. A. Campbell, Jr. \\ Departments of Surgery, Pathology, ${ }^{*}$ and Medicine, ${ }^{\ddagger}$ University of Michigan Medical Center, Ann Arbor, Michigan 48109
}

\begin{abstract}
Cytokines are recognized as critical early mediators of organ injury. We attempted to determine whether or not severe hepatic ischemia/reperfusion injury results in tumor necrosis factor- $\alpha(T N F-\alpha)$ release with subsequent local and systemic tissue injury. After 90 min of lobar hepatic ischemia, TNF was measurable during the reperfusion period in the plasma of all 14 experimental animals, with levels peaking between 9 and $352 \mathrm{pg} / \mathrm{ml}$. Endotoxin was undetectable in the plasma of these animals. Pulmonary injury, as evidenced by a neutrophilic infiltrate, edema and intra-alveolar hemorrhage developed after hepatic reperfusion. The neutrophilic infiltrate was quantitated using a myeloperoxidase (MPO) assay; this demonstrated a significant increase in MPO after only $1 \mathrm{~h}$ of reperfusion. Anti-TNF antiserum pretreatment significantly reduced the pulmonary MPO after hepatic reperfusion. After a 12-h reperfusion period, there was histologic evidence of intra-alveolar hemorrhage and pulmonary edema. Morphometric assessment showed that pretreatment with anti-TNF antiserum was able to completely inhibit the development of pulmonary edema. Liver injury was quantitated by measuring serum glutamic pyruvic transaminase which showed peaks at 3 and $24 \mathrm{~h}$. Anti-TNF antiserum pretreatment was able to significantly reduce both of these peak elevations. These data show that hepatic ischemia/reperfusion results in TNF production, and that this TNF is intimately associated with pulmonary and hepatic injury. (J. Clin. Invest. 1990. 85:1936-1943.) hepatic injury • ischemia • lung injury • reperfusion • tumor necrosis factor
\end{abstract}

\section{Introduction}

Extrapulmonary organ failure in association with the adult respiratory distress syndrome (ARDS) ${ }^{1}$ increases the mortality of ARDS (1-3). Recent clinical data have shown that impaired hepatic function greatly influences severity and impedes resolution of ARDS (4). Patients with end-stage liver disease are at increased risk of developing ARDS; primary nonfunction of

Address reprint requests to Dr. Remick, Department of Pathology, Box 0602, 1301 Catherine Road, University of Michigan Medical School, Ann Arbor, MI 48109-0602.

Received for publication 31 May 1989 and in revised form 5 February 1990.

1. Abbreviations used in this paper: ARDS, adult respiratory distress syndrome; HPF, high-power field; MPO, myeloperoxidase; PCA, perchloric acid; SGPT, serum glumatic pyruvic transaminase; TNF, rTNF, tumor necrosis factor, recombinant TNF.

J. Clin. Invest.

(C) The American Society for Clinical Investigation, Inc.

$0021-9738 / 90 / 06 / 1943 / 08 \quad \$ 2.00$

Volume 85, June 1990, 1936-1943 the graft after liver transplantation is also associated with the rapid development of pulmonary insufficiency (5). A potential explanation for the association of liver injury with pulmonary insufficiency involves cytokine release by injured hepatic tissue. Since the pulmonary circulation represents the first vascular bed into which these cytokines are delivered, the pulmonary parenchyma would be likely to manifest the toxic effects of these cytokines. In this study, we tested the hypothesis that tumor necrosis factor (TNF) released from ischemically damaged liver mediates subsequent pulmonary injury. Previous studies support this hypothesis since intravenously injected recombinant TNF (rTNF) is known to cause pulmonary hemorrhage and edema $(6,7)$. Furthermore, the liver should have a substantial capacity for TNF production since TNF is produced primarily by cells of the monocyte/macrophage lineage and the liver Kupffer cell mass is the largest fixed macrophage population in the body. Experiments were therefore designed to test whether profound hepatic ischemia and subsequent reperfusion triggers TNF release, and whether this phenomenon is associated with a reproducible pulmonary injury. In addition to assessing the role of TNF in remote organ injury, we also evaluated the role of TNF in the pathogenesis of the local hepatic injury which follows an ischemic insult.

\section{Methods}

Animal model. By utilizing a rat model of lobar, rather than total, hepatic ischemia, a severe ischemic insult was produced without inducing mesenteric venous hypertension (8). An atraumatic microaneurysm (Heifitz) clip was used to interrupt the portal venous and hepatic arterial blood supply to the cephalad three lobes of the liver. The three caudal lobes retain an intact portal inflow and venous outflow, preventing intestinal venous congestion and possible leakage of bacteria or bacterial products into the circulation.

All experiments utilized adult male pathogen-free Sprague-Dawley rats (Charles River Breeding Laboratories, Inc., Portage, MI). Weights ranged 200-300 g; for each experiment there was $<25 \mathrm{~g}$ difference between animals. After induction of anesthesia with intramuscular ketamine hydrochloride $(100 \mathrm{mg} / \mathrm{kg})$, an indwelling intravenous line was placed via the right external jugular vein for serial blood sampling and administration of intravenous fluids and medications. By positioning the catheter tip in the suprahepatic vena cava just above the dome of the liver, immediately posthepatic blood samples were obtained; correct catheter position was confirmed at laparotomy. After intravenous heparinization with $100 \mathrm{U} / 100 \mathrm{~g}$ of body weight, midline laparotomy was performed. Hepatic ischemia was initiated by application of a Heifitz clip, ischemia was maintained for $90 \mathrm{~min}$, and the Heifitz clip was then removed at a second laparotomy. A 90-min ischemia period was selected since a preliminary study showed that this length of ischemia induced maximum systemic levels of TNF (9). Intravenous lactated Ringer's solution in a dose of $0.75 \mathrm{ml}$ was administered to replace operative fluid and blood losses. Sham-operated control animals were treated in an identical fashion with the omission of vascular occlusion.

Blood sampling for TNF. 14 rats were subjected to lobar hepatic ischemia and reperfusion as described above. Blood was sampled from 
the indwelling suprahepatic catheter before clamp placement, immediately before clamp removal, immediately after clamp removal, and after $15 \mathrm{~min}$ to $24 \mathrm{~h}$ of reperfusion. The blood was collected by drawing sufficient volume from the central line to obtain blood, then a 300- $\mu$ l sample of blood was removed. The initial volume was then reinjected back into the rat along with $300 \mu$ l of lactated Ringer's solution to replace the lost blood volume. Plasma was separated from the samples and stored at $-20^{\circ} \mathrm{C}$ until assayed. Blood sampling at identical time points was performed in three sham-operated control animals.

TNF assay. TNF activity in the plasma specimens was measured using a sensitive bioassay with the WEHI 164 , subclone 13 cell line as previously described (10). Briefly, plasma samples were serially diluted directly into 96-well flat-bottom cell culture trays and $100 \mu \mathrm{l}$ of WEHI cells $\left(5 \times 10^{4}\right.$ cells) with $0.5 \mu \mathrm{g} / \mathrm{ml}$ actinomycin $\mathrm{D}$ (Calbiochem-Behring Corp., LaJolla, CA), were added to each well. The plates were incubated for $20 \mathrm{~h}$ at $37^{\circ} \mathrm{C}$. After the addition of $20 \mu \mathrm{l}$ of 3-(4,5-dimethlythiiazol-2-yl)-2,5-diphenlytetrazolium bromide (Sigma Chemical Co., St. Louis, MO) at a concentration of $5 \mathrm{mg} / \mathrm{ml}$ in phosphatebuffered saline to each well, the plates were again incubated at $37^{\circ} \mathrm{C}$ for $4 \mathrm{~h}$. Next, $150 \mu \mathrm{l}$ of media was removed and $100 \mu \mathrm{l}$ of isopropanol with $0.04 \mathrm{~N}$ hydrochloric acid was added to each well to dissolve the purple formazan crystals and the plates were read on an ELISA reader (BioTek Instruments, Inc., Winooski, VT) at an absorbance of $550 \mathrm{~nm}$. A standard curve utilizing human rTNF was generated with each assay and used to calculate TNF values in the experimental samples. The assay was repeated after the positive samples were neutralized with a polyclonal rabbit anti-murine TNF antiserum which cross-reacts with rat $\operatorname{TNF}(11,12)$. A negative assay after this treatment confirmed that the cytotoxic activity was due to TNF.

Blood pressure monitoring. An indwelling catheter was placed into the right carotid artery for blood pressure monitoring. An incision was made in the right neck, the common carotid artery was isolated and a soft silastic catheter (i.d. 0.025 in and o.d. 0.047 in, Dow Corning Corp., Midland, MI) was placed and secured within the vessel. This was connected to a pressure transducer and blood pressure was continuously monitored using a monitor (Hewlett-Packard Co., Corvallis, OR) throughout both laparotomies and for a 1-h period after hepatic revascularization.

Anti-TNF antiserum. The effects of TNF blockade in our model was assessed by administration of a polyclonal rabbit anti-murine TNF antiserum described above $(11,12)$. This antiserum neutralizes both natural and recombinant TNF, cross-reacts with rat TNF and has no cross-reactivity with interleukin 1. After 1:1 dilution of the antiserum with RPMI 1640 (Whitaker Biomedical Products, Whitaker, CA) and immediately before induction of hepatic ischemia, $2 \mathrm{ml}$ of diluted antiserum was given intravenously. Control rats received serum from unimmunized rabbits in an identical manner (control serum).

Limulus assay. A perchloric acid (PCA) modification (13) of the standard chromogenic limulus assay was used to determine if endotoxin was present in the portal venous and/or systemic venous blood in sham-operated control animals or in animals which were subjected to $90 \mathrm{~min}$ of hepatic ischemia. The assay was performed as follows: $0.2 \mathrm{ml}$ of $0.32 \mathrm{~mol} /$ liter PCA was added to $0.1 \mathrm{ml}$ of sample in an ice bath and the mixture was then incubated at $37^{\circ} \mathrm{C}$ for $20 \mathrm{~min}$. The denatured material was centrifuged at $12,000 \mathrm{rpm}$ for $15 \mathrm{~min}$ and the resulting supernatant neutralized by addition of an equal volume of $0.18 \mathrm{~N}$ $\mathrm{NaOH}$. A standard curve was generated by adding lipopolysaccharide (LPS) (Escherichia coli type 0111:B4, Sigma Chemical Co.) to fetal calf serum and treating the samples with PCA as described above. This standard curve was then analyzed using the chromogenic Limulus amebocyte lysate assay according to the manufacturer's instructions (Whitaker, Walkersville, MD). The lower limit of endotoxin detection in this assay is $5 \mathrm{pg} / \mathrm{ml}$.

Assessment of organ injury. After hepatic ischemia/reperfusion the liver and the lungs showed both gross and microscopic evidence of injury. Organ injury was evaluated at each time point in a separate group of rats which did not undergo the repeated early blood sampling for TNF measurement, since the early removal of blood may have exacerbated the injury induced by hepatic ischemia/reperfusion. Quantitation of lung injury was done by the myeloperoxidase assay for neutrophils and morphometric assessment of pulmonary edema; the hepatic injury was quantitated by measurement of serum glutamic pyruvic transaminase (SGPT).

Myeloperoxidase (MPO) assay. Pulmonary neutrophil sequestration was quantitated with the MPO assay (14). At the time of sacrifice, $10 \mathrm{ml}$ of saline were injected into the spontaneously beating right ventricle to flush the lungs of intravascular pulmonary blood. The left lung was excised and placed in a $50 \mathrm{mM}$ phosphate buffer $(\mathrm{pH}=6.0)$ with $5 \%$ hexadecyltrimethyl ammonium bromide (Sigma Chem. Co.). The pulmonary tissue was homogenized, sonicated, and centrifuged at $12,000 \mathrm{~g}$ for $15 \mathrm{~min}$ at $4^{\circ} \mathrm{C}$. The resultant supernatant was assayed for MPO activity using a spectrophotometric reaction with $O$-dianisidine hydrochloride (Sigma Chemical Co.) at $460 \mathrm{~nm}$.

The right lung was insuflated with normal buffered formalin via the right main stem bronchus, excised, and stored in formalin.

Histology. Lung and liver blocks were embedded in paraffin; $5-\mu \mathrm{m}$ sections were cut and stained with hematoxylin and eosin. Slides were examined in a blinded manner. Pulmonary injury was quantitated morphometrically on histologic sections based on a modification of our previously described technique (12). Briefly, 100 randomly selected high-power fields (HPF) were examined from each animal and the number of edema-filled aveoli per high-power field was determined. The group mean was calculated by averaging the mean count from each animal.

Measurement of serum liver enzymes. Blood samples for measurement of serum SGPT were obtained at various time points via the indwelling venous line. SGPT was quantitated using standard clinical automated analysis. Blood volume was replaced on a milliliter per milliliter basis with lactated Ringer's solution. This blood sampling was done in a separate group of rats which did not undergo the repeated early sampling for TNF measurements; also, these animals were not used for assessment of pulmonary injury.

Statistical analysis. Unless otherwise noted, mean minimum systolic blood pressure (torr) and myeloperoxidase levels (units) are expressed as the mean \pm standard error of the mean (SEM). Serum SGPT is expressed in international units/liter \pm SEM. The Student NewmanKeuls test (15) was used to compare groups, however, if the data was not normally distributed, we used the nonparametric Wilcoxon ranksum test.

\section{Results}

TNF release after hepatic ischemia/reperfusion. After hepatic ischemia and reperfusion, TNF was measurable in the plasma of all 14 experimental animals (Fig. 1), whereas TNF was undetectable at any time point in the three sham-operated control animals. The time point at which the TNF level peaked was somewhat variable, occurring between $30 \mathrm{~min}$ and $3 \mathrm{~h}$ after reperfusion. The mean peak TNF level was $69.4 \pm 30.3$ $\mathrm{pg} / \mathrm{ml}$ with a range of $9-352 \mathrm{pg} / \mathrm{ml}$. To confirm that the bioactivity measured in this assay was due to TNF, selected positive samples were incubated with anti-TNF antibody before assay. This pretreatment completely blocked the bioactivity of the positive samples. In addition, endotoxin was undetectable $(<5 \mathrm{pg} / \mathrm{ml})$.

Hemodynamic monitoring and instability. Blood pressure was monitored in four groups of animals: a sham-operated group $(n=5)$, a group of animals which were subjected to hepatic ischemia and reperfusion alone $(n=6)$, an anti-TNF antiserum-treated group $(n=6)$, and a control serum-treated group $(n=6)$. None of these animals had blood withdrawn for TNF measurements. All animals in the sham-operated control 


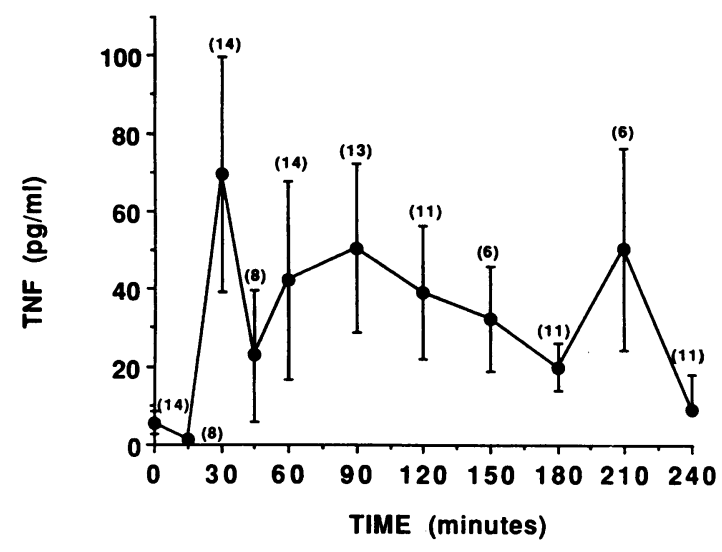

Figure 1. Kinetics of TNF production after hepatic ischemia/reperfusion. 14 rats were subjected to lobar hepatic ischemia/reperfusion and TNF measured in the plasma at the indicated time points. Time 0 indicates the beginning of hepatic revascularization, and TNF bioactivity was detected within $30 \mathrm{~min} .13$ of the 14 rats had peak TNF levels occurring between $30 \mathrm{~min}$ and $2 \mathrm{~h}$. Each point is the mean \pm SEM, the number of rats in each group is indicated by the number in parenthesis.

group were hemodynamically stable throughout the observation period whereas all animals in the remaining experimental groups were hemodynamically stable until hepatic revascularization. 10-20 min after hepatic revascularization, the animals became transiently hypotensive. For animals undergoing hepatic ischemia and reperfusion alone, the mean minimum systolic blood was significantly different from sham-operated animals $(P<0.005)$. The mean minimum systolic blood pressure for animals treated with either anti-TNF antiserum or control serum was also statistically different from sham-operated animals $(P<0.005$ for both groups). Thus, the anti-TNF antiserum did not prevent the transient hypotension observed after revascularization (Fig. 2).

Pulmonary neutrophil sequestration. The pulmonary injury in this model was initially evaluated by measuring lung MPO activity. This has reliably been used as a quantitative measure of pulmonary neutrophil infiltration $(11,12,14)$. The kinetics of pulmonary neutrophil infiltration after hepatic reperfusion were determined by measuring pulmonary MPO content in five groups of rats: a sham group $(n=5)$ and groups at $1(n=5), 3(n=5), 6(n=4)$, and $12(n=6)$ h postreperfusion. MPO levels were maximal after $1 \mathrm{~h}$ of reperfusion and gradually decreased over the next $11 \mathrm{~h}$. Sham-operated control animals also had lung MPO activity measured at time points after the second laparotomy which corresponded to the length of reperfusion time. All the sham animals had essentially the same values; the data in Fig. 3 is from shams matched to point of maximal MPO activity. $1 \mathrm{~h}$ postrevascularization, mean pulmonary MPO was $0.653 \pm 0.089 \mathrm{U}$ as compared with $0.213 \pm 0.034 U$ for sham-operated animals $(P<0.005$; Fig. 3.).

The role of TNF in eliciting pulmonary neutrophil sequestration was investigated by treating one group of rats $(n=10)$ with anti-TNF antiserum and a second group $(n=5)$ with control serum as previously described. Pulmonary MPO was measured at $1 \mathrm{~h}$ of reperfusion, since this represented the time of peak activities. The data from the sham and $1 \mathrm{~h}$ from Fig. 3 is shown again for comparison. The mean MPO in anti-TNF antiserum-treated animals was $0.458 \pm 0.057 \mathrm{U}$ and was signifi-

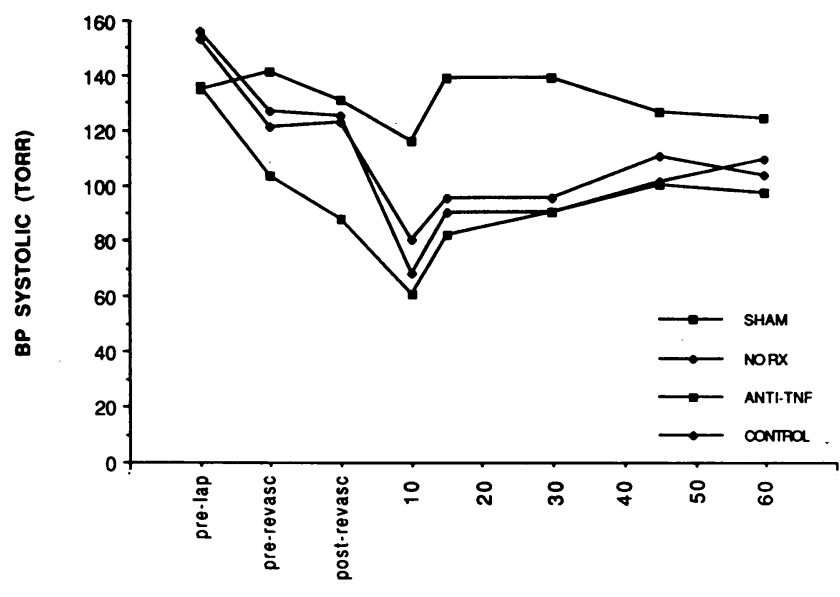

REPERFUSION TIME (MINUTES)

Figure 2. Mean systolic blood pressure before and after hepatic reperfusion. Four treatment groups are illustrated. Sham indicates animals which underwent sham laparotomy only. (NO RX, $)$ Rats that were subjected to $90 \mathrm{~min}$ of lobar hepatic ischemia and subsequent reperfusion and did not receive any rabbit serum. $(A N T I-T N F, \square)$ Animals that were treated with rabbit anti-TNF antiserum before the induction of hepatic ischemia; $(C O N T R O L, \diamond)$ animals that were pretreated with rabbit serum without TNF blocking activity. Reperfusion time is represented on the $x$-axis; pre-lap indicates a time point preceding laparotomy, pre-revasc indicates the time point immediately before hepatic revascularization and post-revasc represents the time point immediately after hepatic revascularization. Other time points represent reperfusion times in minutes.

cantly reduced $(P<0.005)$ as compared with the mean MPO levels in the control serum-treated animals $(0.701 \pm 0.040 \mathrm{U}$; Fig. 4.). Thus, anti-TNF treatment blunted the increase in pulmonary MPO but did not reduce the MPO level to that observed in sham-operated controls.

Pulmonary histology. Pulmonary histology was assessed in sham-operated control animals $(n=5)$ and in animals subjected to hepatic ischemia followed by $12 \mathrm{~h}$ of reperfusion ( $n$ $=4$ ). There was minimal to no evidence of pulmonary edema in the sham-operated group. However, following a 12-h reper-

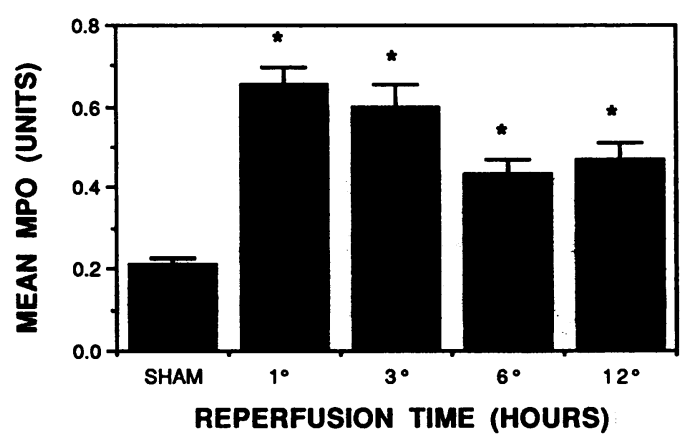

Figure 3. Kinetics of pulmonary neutrophil infiltration. Neutrophilic infiltrate was assessed by a MPO assay at the indicated times of reperfusion following the standard 90-min ischemic period. MPO levels peaked after $1 \mathrm{~h}$ of hepatic reperfusion and then declined. ${ }^{*} P<0.005$ compared to sham-operated controls. Each group is the mean \pm SEM. 


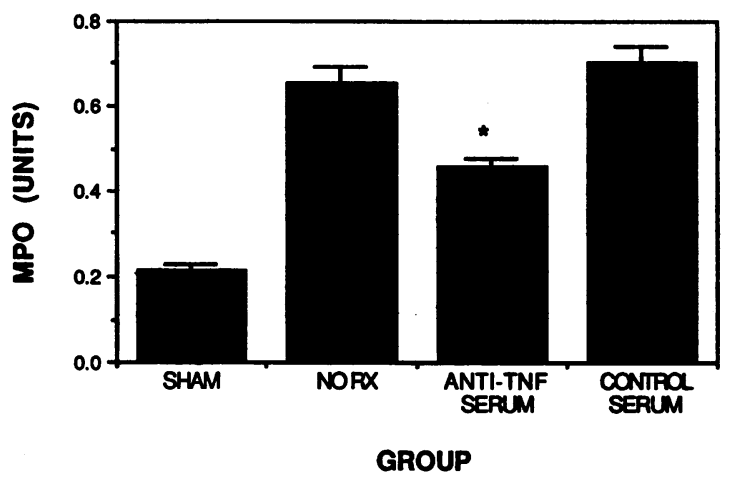

Figure 4. Pulmonary MPO after antiserum treatments. After hepatic ischemia and $1 \mathrm{~h}$ of reperfusion pulmonary MPO was measured. (SHAM) Sham-operated control animals. (NO RX) ischemia and reperfusion alone. (ANTI-TNF SERUM and CONTROL) Animals that were pretreated with the respective sera. The anti-TNF antiserum significantly decreased the neutrophilic infiltrate, but did not return the values to baseline. ${ }^{*} P<0.005$ compared with both the untreated experimental animals and animals pretreated with control serum. Each group is the mean \pm SEM.

fusion period, there was obvious pulmonary edema; patchy intra-alveolar hemorrhage was also present.

Since easily distinguishable intra-alveolar hemorrhage and pulmonary edema were present after a 12 -h reperfusion period, pulmonary histology was evaluated at this time point in animals which were treated with anti-TNF antiserum $(n=5)$ or control serum $(n=3)$ before the induction of hepatic ischemia. Anti-TNF antiserum treatment conferred significant protection from pulmonary damage. Control serum treated animals had a mean of $20 \pm 4$ flooded alveoli/HPF in contrast to $0 \pm 0$ flooded alveoli/HPF in the anti-TNF antiserumtreated group ( $P<0.05$ by Wilcoxon rank sum test). These data confirm our earlier study which used an intravenous radioactive tracer to document protein leakage into the lungs (9). Fig. 5 is a composite showing pulmonary histology in shamoperated animals, in animals subjected to hepatic ischemia/ reperfusion alone and in animals subjected to hepatic ischemia/reperfusion after treatment with either control serum or anti-TNF antiserum.

Assessment of liver injury. Microscopic examination of the liver after $24 \mathrm{~h}$ of reperfusion showed severe injury in the ischemic lobes, centered primarily about the central vein. This consisted of hepatocyte necrosis and neutrophilic infiltration (Fig. 6). Serum samples for SGPT determination were obtained before induction of hepatic ischemia and after 1, 3, 6, 9, 12 , and $24 \mathrm{~h}$ of reperfusion. Serum samples were also obtained from sham-operated controls after the second laparotomy at time points which corresponded to the reperfusion time. SGPT levels after all reperfusion periods were significantly different from controls $(P<0.05$ at least for each group). However, the most significant SGPT elevations were seen 3 and $24 \mathrm{~h}$ postrevascularization $(P<0.005$ and $<0.001$, respectively, compared with time-matched sham controls; Fig. 7.) To assess the role of TNF in this injury, four groups of rats were evaluated: a sham-operated control group $(n=5)$, a group undergoing hepatic ischemia and reperfusion alone ( $n$ $=10$ ), and groups which were treated with anti-TNF antiserum $(n=6)$ or control serum $(n=11)$ before induction of hepatic ischemia. Blood samples for SGPT determination were obtained at $3 \mathrm{~h}$ and again at $24 \mathrm{~h}$ of hepatic reperfusion. SGPT levels were significantly decreased both 3 and $24 \mathrm{~h}$ postrevascularization in the animals treated with anti-TNF antiserum as compared to untreated experimental animals and animals treated with control serum $(P<0.05$ after $3 \mathrm{~h}$ of reperfusion and $P<0.005$ after $24 \mathrm{~h}$ of reperfusion for both groups). The enzyme levels in animals treated with control serum were not significantly different from untreated experimental animals, and were significantly different from the enzyme levels in sham-operated control animals $(P<0.005$ at both time points; Fig. 8.)

24-h survival. Of 24 animals undergoing 90 min of lobar hepatic ischemia and $24 \mathrm{~h}$ of reperfusion, eight animals expired before $24 \mathrm{~h}$, resulting in a 24-h survival of $67 \%$. In contrast, of 12 animals treated with anti-TNF antiserum before the induction of hepatic ischemia, 11 animals survived for 24 h, giving a $24-\mathrm{h}$ survival of $92 \%$. $24 \mathrm{~h}$ survival in animals treated with control serum was similar to that seen in the untreated experimental group with 6 of 10 animals surviving for $24 \mathrm{~h}$. The survival rates were compared using a $\chi^{2}$ test. Statistical significance was not achieved between any of the groups, most likely due to the relatively small numbers in the groups.

\section{Discussion}

The role of TNF in septic shock in both experimental models $(6,7,11,16-18)$ and clinical medicine (19-21) has been a subject of great interest $(6,7,11)$. TNF appears to be involved in many types of inflammatory processes, and has recently been detected in specific disease states including parasitic infections $(22,23)$, renal allograft rejection (24), in joint effusions of arthritic patients (25), and in patients with the acquired immunodeficiency syndrome (AIDS) (26). In some cases, an increased level of TNF has been correlated with severity of disease $(19,22,26)$. The data presented in this communication demonstrate that TNF is produced after lobar hepatic ischemia/reperfusion and that a picture of pulmonary neutrophil sequestration and hemorrhagic edema develops. The pulmonary pathology appears to be a consequence of TNF, since pretreatment with neutralizing anti-TNF antiserum blunted the neutrophilic infiltrate (as measured by MPO) and completely abolished both the diffuse edema and patchy hemorrhage. These findings are consistent with the pulmonary injury seen after direct intravenous infusion of rTNF into rats. Pathologic examination of lung tissue from rTNF infused these animals revealed diffuse hyperemia with punctate hemorrhage, neutrophil thrombi and severe interstitial and peribronchiolar pneumonitis (6). We also noted that pretreatment of rats undergoing hepatic ischemia/reperfusion with anti-TNF antiserum substantially reduces the liver injury which occurs under the circumstances of the experimental model. Our data thus describes a model of hepatic ischemia/ reperfusion in which both local (hepatic) and systemic (pulmonary) injury is produced via the effects of a critical cytokine, TNF.

The mechanism of induction of TNF bioactivity after hepatic ischemia/reperfusion is not completely clear, but it seems likely that the process of ischemia/reperfusion induces hepatic macrophages (Kupffer cells) to produce or "leak" this cytokine into the systemic circulation. Although other cells are capable 

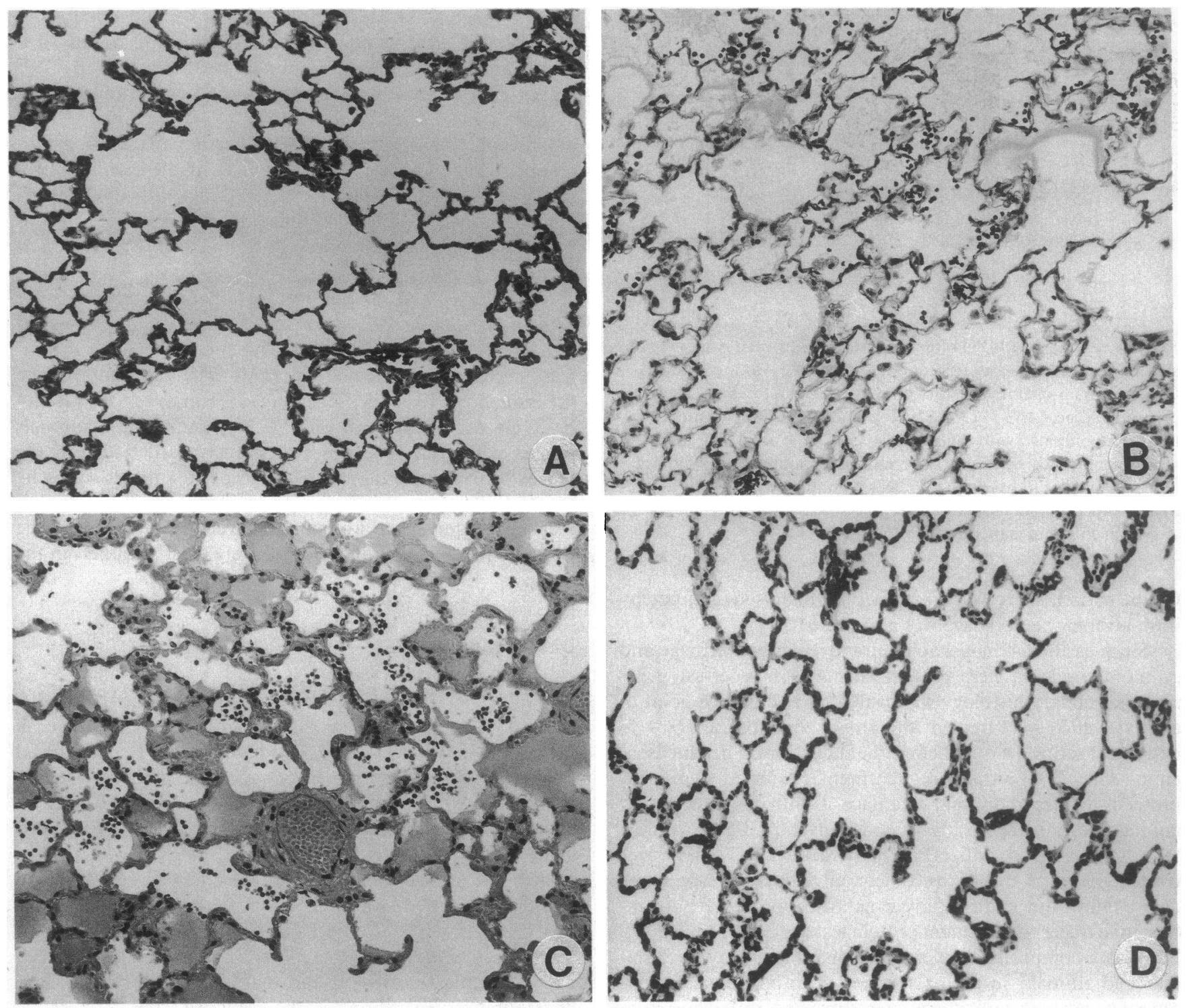

Figure 5. Pulmonary histology after hepatic ischemia/reperfusion and anti-TNF antiserum treatment. Rats were subjected to 90 min of ischemia and after $12 \mathrm{~h}$ of reperfusion, the lungs were examined histologically. $(A)$ Sham-operated controls have normal histology, whereas $(B)$ the operated rats show intra-alveolar hemorrhage and some edema fluid. $(C)$ Rats pretreated with control serum also have intra-alveolar edema fluid and hemorrhage, whereas $(D)$ the anti-TNF-treated rats illustrate essentially normal histology. All panels $\times 165$.

of TNF production if properly stimulated, macrophages appear to be the principal source of TNF (27). The Kupffer cell population within the liver is the largest fixed macrophage population in the body and the liver, therefore, has a vast potential for TNF release. Previous in vitro studies have documented the ability of Kupffer cells to produce TNF (28). Further, the kinetics of TNF production in our model are consistent with the kinetics seen in other in vivo models of TNF production, i.e., rapid production of TNF followed by rapid clearance $(16,29)$.

An important potential mechanism for TNF production in this model involves the exposure of macrophages to LPS in the portal or arterial blood. It was conceivable that the lobar ischemia resulted in mesenteric venous congestion, transmigration of bacteria or LPS into the portal effluent and Kupffer cell exposure. Such an occurrence has been documented after transient occlusion of the superior mesenteric artery and vein, with TNF release and consequent pathology (30). However, our model was specifically chosen to avoid such vascular congestion, involving only lobar vascular occlusion with unimpeded portal flow to the right lobe. In fact, sensitive measurements for LPS in the portal and systemic blood failed to detect LPS. We conclude that the TNF measured in this set of circumstances is not LPS dependent. The TNF release also did not appear directly related to the hypotensive effect produced by the I/R process, since anti-TNF antiserum treatment blocked the observed pathology, but did not alter the hypotension following clamp release.

Since TNF has a multitude of effects on neutrophil (PMN) function (31-34) and MPO activity, indicative of PMNs, was detected in the lungs after reperfusion, it was important to assess the role of TNF in PMN accumulation. TNF could act 



Figure 6. Hepatic histology after ischemia/reperfusion. A section of the ischemic liver was examined histologically. $(A)$ After $1 \mathrm{~h}$ of reperfusion, there is essentially normal hepatic histology. $(B)$ After $24 \mathrm{~h}$ a pattern of ischemic damage is evident with loss of hepatocytes in the central vein region with relative sparing near the portal triad. CV, central vein; PT, portal triad. Both panels $\times 82$.

to increase either the expression of endothelial cell-based adherence proteins for neutrophils or increase the expression of neutrophil-based adherence proteins for endothelial cells (31, 32). TNF may also increase the susceptibility of the vascular endothelium to neutrophil-mediated attack (35), and induce neutrophils to produce superoxide anion and hydrogen perox-

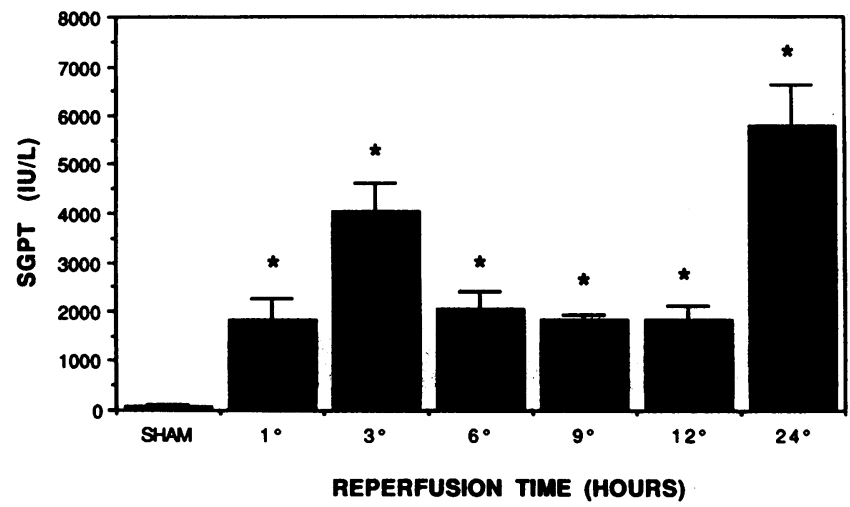

Figure 7. Liver enzyme kinetics. Mean SGPT levels after varying periods of hepatic reperfusion are illustrated. Peak enzyme levels occurred after 3 and $24 \mathrm{~h}$ of reperfusion. ${ }^{*} P<0.05$ compared to timematched shams. Each value is the mean \pm SEM; the displayed sham value is from $24 \mathrm{~h}$ after the second laparotomy. ide or other toxic metabolites $(33,34)$. In addition, TNF has been shown to induce endothelial cells to produce a variety of cytokines, including interleukin-1 (36), platelet-derived growth factor (PDGF) (37), platelet-activating factor (PAF) (38), neutrophil chemotactic factor (NCF) (39), and tissue factor-like protein with procoagulant activity (40). While the temporal sequence of events in the lung is consistent with a central role for neutrophils, with neutrophil infiltration peaking at $1 \mathrm{~h}$ and the subsequent severe endothelial injury peaking at 9-12 $\mathrm{h}$ after reperfusion, it is also plausible that endothelial cells escalate the neutrophil-mediated inflammation by the elaboration of cytokines capable of neutrophil chemotaxis and stimulation. Pulmonary neutrophil infiltration in this model was only partially blocked by the anti-TNF antiserum which almost completely abrogated the microvascular leak and hemorrhagic edema. Although neutrophil sequestration in the lung was reduced it was not returned to the level of sham operated controls. We reported a similar finding in an endotoxin model of septic shock, i.e., anti-TNF antiserum does not completely inhibit neutrophil sequestration in the lung (11). It is possible that the substantial influx of neutrophils noted was collectively the result of many stimuli of which TNF was only one. Interleukin 1, for example, is another cytokine produced by macrophages and endothelial cells which has substantial effects on neutrophil migration and function (41-44). The anti-TNF antiserum used in these experiments does not have any anti-interleukin 1 activity (11). Similar experiments with neutrophil 

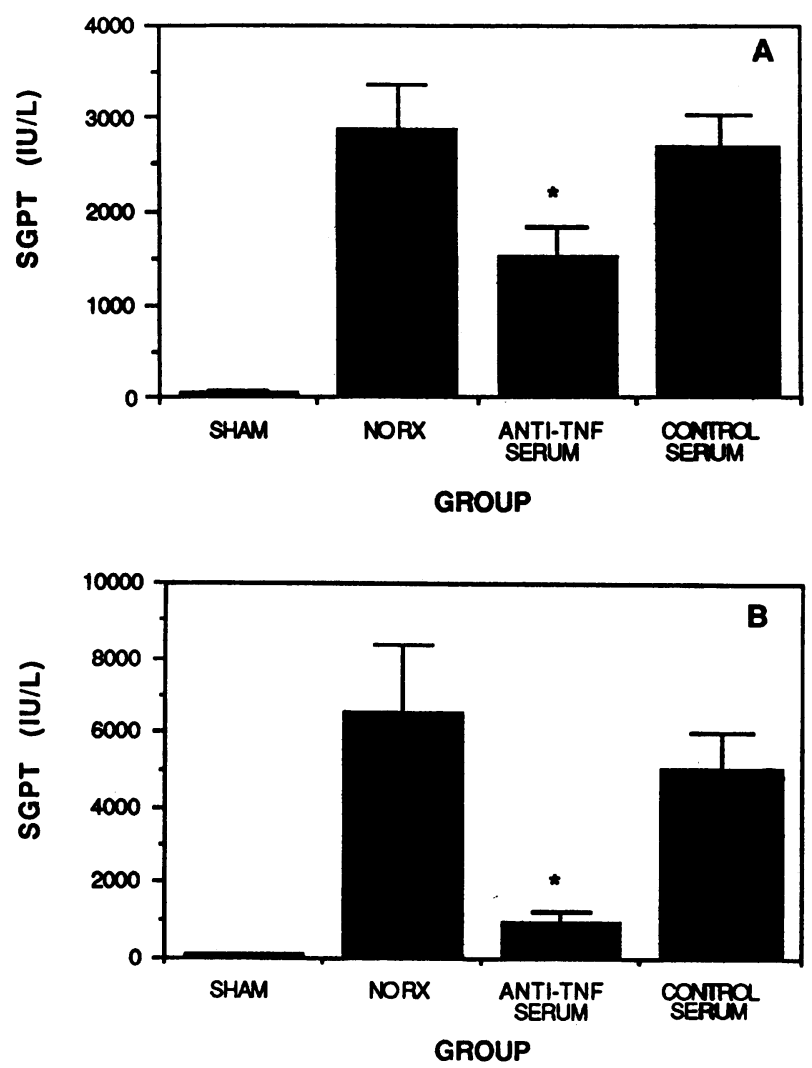

Figure 8. SGPT after 3 and $24 \mathrm{~h}$ of reperfusion after various antiserum treatments. ( $S H A M)$ Sham-operated control animals; (NO $R X)$ animals subjected to hepatic ischemia and reperfusion alone; (ANTI-TNF SERUM and CONTROL SERUM) animals that were pretreated with the respective sera. $(A)$ After $3 \mathrm{~h}$ of hepatic reperfusion, there was a significant decrease in SGPT in animals pretreated with anti-TNF antiserum as compared with both the untreated experimental animals and the control serum-treated animals. (B) Similarly, after $24 \mathrm{~h}$ of hepatic reperfusion, there was a significant decrease in SGPT in the anti-TNF antiserum-treated animals as compared with the untreated experimental animals and the control serum treated animals. ${ }^{*} P<0.05$ as compared with untreated experimental animals and control serum-treated animals.

depleted animals are planned to further assess the role of the neutrophil in the observed pathology.

Animals treated with anti-TNF antiserum showed a significant reduction in a hepatocyte-specific enzyme (SGPT) after hepatic ischemia/reperfusion in comparison to controls treated with control serum, suggesting that TNF may mediate hepatocyte injury. This was not the result of protection from a hypotensive effect, since the anti-TNF and control serum groups showed the same degree of transient hypotension after clamp release. Previous studies have documented a deleterious effect of TNF on the hepatocyte where infused rTNF results in focal hepatic necrosis, as does LPS infusion, and the latter finding could be blocked with anti-TNF antiserum (13).

Taken together, these data suggest that the process of hepatic ischemia/reperfusion results in TNF release, and that TNF has both local deleterious effects on the hepatocyte and extensive damaging effects on pulmonary integrity. Although there is extensive neutrophilic infiltration in lungs, further studies are needed to document the degree to which the observed pathology is neutrophil dependent.

\section{Acknowledgments}

This study was supported in part by National Institute of Health grants HL31237, HL31963, HL35276, and HL39339 and grant-in-aid from the American Heart Association of Michigan. Dr. Kunkel is an Established Investigator of the American Heart Association.

\section{References}

1. Fein, A. M., M. Lippman, H. Holtsman, A. Eliraz, and S. K. Goldberg. 1983. The risk factors, incidence, and prognosis of ARDS following septicemia. Chest. 83:40-42.

2. Bell, R. C., J. J. Coalson, J. D. Smith, and W. G. Johanson. 1980. Multiple organ system failure and infection in adult respiratory distress syndrome. Ann. Intern. Med. 99:293-298.

3. Fowler, A. A., R. F. Hamman, G. O. Zerbe, K. N. Benson, and T. M. Hyers. 1985. Adult respiratory distress syndrome: prognosis after onset. Am. Rev. Respir. Dis. 132:472-478.

4. Matuschak, G. M., and J. E. Rinaldo. 1988. Organ interaction in the adult respiratory distress syndrome during sepsis. Chest. 94:400406.

5. Matuschak, G. M., J. E. Rinaldo, M. R. Pinsky, J. S. Gavaler, and D. H. Van Thiel. 1987. Effect of end stage liver failure on the incidence and resolution of the adult respiratory distress syndrome. $J$. Crit. Care. 2:162-173.

6. Tracey, K. J., B. Beutler, S. F. Lowry, J. Merryweather, S. Wolpe, I. W. Milsark, R. J. Hariri, T. J. Fahey, A. Zentalla, J. D. Albert, et al. 1986. Shock and tissue injury induced by recombinant human cachectin. Science (Wash. DC). 234:470-474.

7. Tracey, K. J., S. F. Lowry, T. S. Fahey, J. D. Albert, Y. Fong, D. Hesse, B. Beutler, K. R. Manogue, S. Calvano, H. Wei, et al. 1987. Cachectin/tumor necrosis factor induces lethal shock and stress hormone responses in the dog. Surg. Gynecol. Obstet. 164:415-422.

8. Hayashi, H., I. H. Chaudry, M. G. Clemens, and A. E. Baue. 1986. Hepatic ischemia models for determining the effects of ATP$\mathrm{MgCl}_{2}$ treatment. J. Surg. Res. 40:167-175.

9. Colletti, L. M., G. D. Burtch, D. G. Remick, S. L. Kunkel, R. M. Strieter, K. S. Guice, K. T. Oldham, and D. A. Campbell. 1989. Production of tumor necrosis factor alpha and the development of a pulmonary capillary injury following hepatic ischemia/reperfusion. Transplantation (Baltimore). 49:268-273.

10. Espevik, T., and J. Nissen-Meyer. 1986. A highly sensitive cell line, WEHI 164 clone 13, for measuring cytotoxic factor/tumor necrosis factor from human monocytes. J. Immunol. Methods. 95:99105.

11. Remick, D. G., R. M. Strieter, M. K. Eskandari, D. T. Nguyen, M. A. Genord, C. L. Raiford, and S. L. Kunkel. 1990. Role of tumor necrosis factor alpha in lipopolysaccharide induced pathologic alterations. Am. J. Pathol. 136:49-60.

12. Warren, J. S., K. R. Yabroff, D. G. Remick, S. W. Chenuse, S. L. Kunkel, R. G. Kunkel, K. J. Johnson, and P. A. Ward. 1989. Tumor necrosis factor participates in the pathogenesis of acute immune complex alveolitis in the rat. J. Clin. Invest. 84:1873-1882.

13. Obayashi, T. 1984. Addition of perchloric acid to blood samples for colorimetric limulus test using chromogenic substrate: comparison with conventional procedures and clinical applications. J. Lab. Clin. Med. 104:321-330.

14. Goldblum, S. E., K. M. Wu, and M. Jay. 1985. Lung myeloperoxidase as a measure of pulmonary leukostasis in rabbits. J. Appl. Physiol. 59:1978-1985.

15. Glantz, S. A. 1987. Primer of Biostatistics. 2nd edition. McGraw-Hill Book Co., Inc., New York.

16. Mathison, J. C., E. Wolfson, and R. J. Ulevitch. 1988. Participation of tumor necrosis factor in the mediation of gram negative bacterial lipopolysaccharide-induced injury in rabbits. J. Clin. Invest. 81:1925-1937.

17. Beutler, B., I. W. Milsark, and A. C. Cerami. 1985. Passive 
immunization against cachectin/tumor necrosis factor protects mice from the lethal effect of endotoxin. Science (Wash. DC). 229:869-871.

18. Tracey, K. J., Y. Fong, D. G. Hesse, K. R. Manogue, A. T. Lee, G. C. Kuo, S. F. Lowry, and A. Cerami. 1987. Anti-cachectin/TNF monoclonal antibodies prevent septic shock during lethal bacteremia. Nature (Lond.). 330:662-664.

19. Waage, A., A. Halstensen, and T. Espevik. 1987. Association between tumor necrosis factor in serum and fatal outcome in patients with meningococcal disease. Lancet. 1:355-357.

20. Michie, H. R., K. R. Manogue, D. R. Spriggs, A. Revhaug, S. O'Dwyer, C. A. Dinarello, A. Cerami, S. M. Wolff, and D. W. Wilmore. 1988. Detection of circulating tumor necrosis factor after endotoxin administration. $N$. Engl. J. Med. 318:1481-1486.

21. Girardin, E., G. E. Grau, J. M. Dayer, P. Roux-Lombard, the J5 Study Group, and P. H. Lambert. 1988. Tumor necrosis factor and interleukin-1 in the serum of children with severe infectious purpura. N. Engl. J. Med. 319:397-400.

22. Grau, G. E., T. E. Taylor, M. E. Molyneux, J. J. Wirima, P. Vassalli, M. Hommel, and P. H. Lambert. 1989. Tumor necrosis factor and disease severity in children with falciparum malaria. $N$. Engl. J. Med. 320:1586-1591.

23. Scuderi, P., K. E. Sterling, K. S. Lam, P. R. Finley, K. J. Ryan, C. G. Ray, E. Peterson, D. J. Slyman, and S. E. Salmon. 1986. Raised serum levels of tumor necrosis factor in parasitic infections. Lancet. 1:1364-1365.

24. Maury, C. J., and A. M. Teppo. 1987. Raised serum levels of cachectin/tumor necrosis factor in renal allograft rejection. J. Exp. Med. 166:1132-1137.

25. Saxne, T., M. A. Palladino, Jr., D. Heinegard, N. Talal, and F. A. Wollheim. 1988. Detection of tumor necrosis factor alpha but not tumor necrosis factor beta in rheumatoid arthritis synovial fluid and serum. Arthritis Rheum. 31:1041-1045.

26. Lahdevirta, J., C. P. Maury, A. M. Teppo, and H. Repo. 1988. Elevated levels of circulating cachectin/tumor necrosis factor in patients with acquired immunodeficiency syndrome. Am. J. Med. 85:289-291.

27. Beutler, B., and A. Cerami. 1987. The endogenous mediator of endotoxic shock. Clin. Res. 35:192-197.

28. Magilavy, D. B., and J. L. Rothstein. 1988. Spontaneous production of tumor necrosis factor alpha by Kupffer cells of MRL/lpr mice. J. Exp. Med. 168:789-794.

29. Remick, D. G., R. M. Strieter, J. P. Lynch III, D. Nguyen, M. Eskandari, and S. L. Kunkel. 1989. In vivo dynamics of murine tumor necrosis factor alpha gene expression: kinetics of dexamethasone-induced suppression. Lab. Invest. 60:766-771.

30. Caty, M. G., D. G. Remick, D. J. Schemling, S. L. Kunkel, K. S. Guice, and K. T. Oldham. Evidence for endotoxin related tumor necrosis factor release in intestinal ischemia-reperfusion. Circ. Shock. 27:365. (Abstr.)

31. Gamble, J. R., J. M. Harlan, S. J. Klebanoff, and M. A. Vadas. 1985. Stimulation of the adherence of neutrophils to umbilical vein endothelium by human tumor necrosis factor. Proc. Natl. Acad. Sci. USA. 82:8667-8671.
32. Pohlman, T. H., K. A. Stanness, P. G. Beatty, H. D. Ochs, and J. M. Harlan. 1986. An endothelial cell surface factor(s) induced in vitro by lipopolysaccharide, interleukin- 1 , and tumor necrosis factor- $\alpha$ increases neutrophil adherences by a CDW18-dependent mechanism. J. Immunol. 136:4548-4553.

33. Klebanoff, S. J., M. A. Vadas, J. M. Harlan, L. H. Sparks, J. R. Gamble, J. M. Agosti, and A. M. Waltersdorph. 1986. Stimulation of neutrophils by tumor necrosis factor. J. Immunol. 136:4220-4225.

34. Shalaby, M. R., B. B. Aggarwal, E. Rinderknecht, L. P. Svedersky, B. S. Finkle, and M. A. Palladino. 1985. Activation of human polymorphonuclear neutrophil functions by interferon-gamma and tumor necrosis factors. J. Immunol. 135:2069-2073.

35. Varani, J., M. J. Bendelow, D. E. Sealey, S. L. Kunkel, D. E. Gannon, U. S. Ryan, and P. A. Ward. 1988. Tumor necrosis factor enhances susceptibility of vascular endothelial cell to neutrophil-mediated killing. Lab. Invest. 59:292-295.

36. Nawroth, P. P., I. Bank, D. Hadley, J. Cassimeris, L. Chess, and D. Stern. 1987. Tumor necrosis factor/cachectin interacts with endothelial cell receptors to induce release of interleukin-1. J. Exp. Med. 163:1363-1375.

37. Hajjar, K. A., D. P. Hajjar, R. L. Silverstein, and R. L. Nackman. 1987. Tumor necrosis factor-mediated release of platelet-derived growth factor from cultured endothelial cells. J. Exp. Med. 16:235245.

38. Camussi, G., F. Bussolino, G. Salvidio, and C. Baglioni. 1987. Tumor necrosis factor/cachectin stimulates peritoneal macrophages, polymorphonuclear leukocytes and vascular endothelial cells to synthesize and release platelet-activating factor. J. Exp. Med. 166:13901394.

39. Kawakani, M., S. Ishibashi, H. Ogawa, T. Murose, F. Takaku, and S. Shibata. 1986. Cachectin/TNF as well as interleukin-1 induces prostacyclin synthesis in cultured vascular endothelial cells. Biochem. Biophys. Res. Commun. 141:482-487.

40. Strieter, R. M., S. L. Kunkel, H. J. Showell, D. G. Remick, S. H. Phan, P. A. Ward, and R. M. Marks. 1988. Endothelial cell gene expression of a neutrophil chemotactic factor by TNF-alpha, LPS, and IL-1-beta. Science (Wash. DC). 243:1467-1469.

41. Bevilacqua, M. P., J. S. Pober, G. R. Majeau, W. Fiers, R. S. Cotran, and M. A. Gimbrone. 1986. Recombinant tumor necrosis factor induces procoagulant activity in cultured human vascular endothelium. Proc. Natl. Acad. Sci. USA. 83:4533-4537.

42. Wankowicz, Z., P. Megyeri, and A. Issekutz. 1988. Synergy between tumor necrosis factor alpha and interleukin- 1 in the induction of polymorphonuclear leukocyte migration during inflammation. $J$. Leukocyte Biol. 43:349-356.

43. Ferrante, A., M. Nandoskar, A. Walz, A. H. Goh, and I. Kowanko. 1988. Effects of tumor necrosis factor alpha and interleukin-1 alpha and beta on human neutrophil migration, respiratory burst and degranulation. Int. Arch. Allergy Appl. Immunol. 86:82-91.

44. Movat, H. Z. 1987. Tumor necrosis factor and interleukin-1: role in acute inflammation and microvascular injury. J. Lab. Clin. Med. 110:668-681. 